\title{
COMUNICACÕES
}

\section{Puccinia heliconiae: agente causal da ferrugem em helicônia cv. Golden Torch no Pará}

\author{
Luiz Sebastião Poltronieri ${ }^{1}$; Jaqueline Rosemeire Verzignassi² ${ }^{2}$ Ruth Linda Benchimol ${ }^{1}$
}

\begin{abstract}
${ }^{1}$ Amazônia Oriental, Tv. Enéas Pinheiro, S/N, CEP 66095-100, Belém, PA; ${ }^{2}$ Embrapa Gado de Corte, Avenida Rádio Maia, 830, Zona Rural, CEP 79106-550, Campo Grande, MS.

Autor para correspondência: Jaqueline Rosemeire Verzignassi (jaqueline.verzignassi@embrapa.br)

Data de chegada: 06/12/2011. Aceito para publicação em: 14/06/2013.
\end{abstract}

A potencialidade natural do Nordeste Paraense para o cultivo de flores tropicais e o apoio governamental para o desenvolvimento desta atividade agrícola, abrem a perspectiva de consolidação da floricultura tropical no Estado, oferecendo mais uma alternativa de agronegócio. Entretanto, as condições de cultivo de flores tropicais no Estado do Pará, relacionadas, principalmente, aos fatores precipitação, umidade e temperatura, favorecem a ocorrência de problemas fitossanitários. Em Benevides (PA) foram coletadas amostras de folhas de Heliconia psittacorum x Heliconia spathocircinata cv. Golden Torch apresentando elevado número de manchas cloróticas com centro marrom-avermelhado e de formato oval (figuras $1 \mathrm{~A}$ e $1 \mathrm{~B}$ ) e que, com a coalescência das lesões, provocava a seca de todo o limbo foliar. Na face abaxial observaram-se numerosas pústulas irregulares, marrons e dispersas pelo limbo, nos tecidos acometidos pelas lesões (Figura 1C). O material coletado foi enviado ao Laboratório de Fitopatologia da Embrapa Amazônia Oriental para identificação do agente causal dadoença. As folhas foram examinadas ao microscópio estereoscópico para a melhor visualização dos sintomas da doença e dos sinais do patógeno. Dos sintomas foram retiradas estruturas (sinais) e preparadas lâminas para observação ao microscópio óptico. A identificação do agente etiológico foi efetuada baseada em literatura pertinente. Os exames efetuados aos microscópios óptico (Figura 1D) e eletrônico de varredura (figuras $1 \mathrm{E}$ e 1F) revelaram a presença de uredósporos originados isoladamente sobre pedúnculos e, conforme descrição de Cummins \& Hiratsuka (Illustrated genera of rust fungi. St.Paul: APS PRESS, 1991.152p.), trata-se do fungo Puccinia heliconiae Diet. Arth., agente causal da ferrugem das helicônias. Este é o primeiro relato deste patógeno em helicônia no Pará, embora já tenha sido relatado em Pernambuco, acometendo várias espécies de helicônia como Heliconia $\mathrm{x}$ nickeriensis (H. psittacorum $\mathrm{x}$ H. marginata), H. psittacorum e H. psittacorum x H. spathocircinata cv. Golden Torch, cv. Red Torch e cv. Torch Adrian.

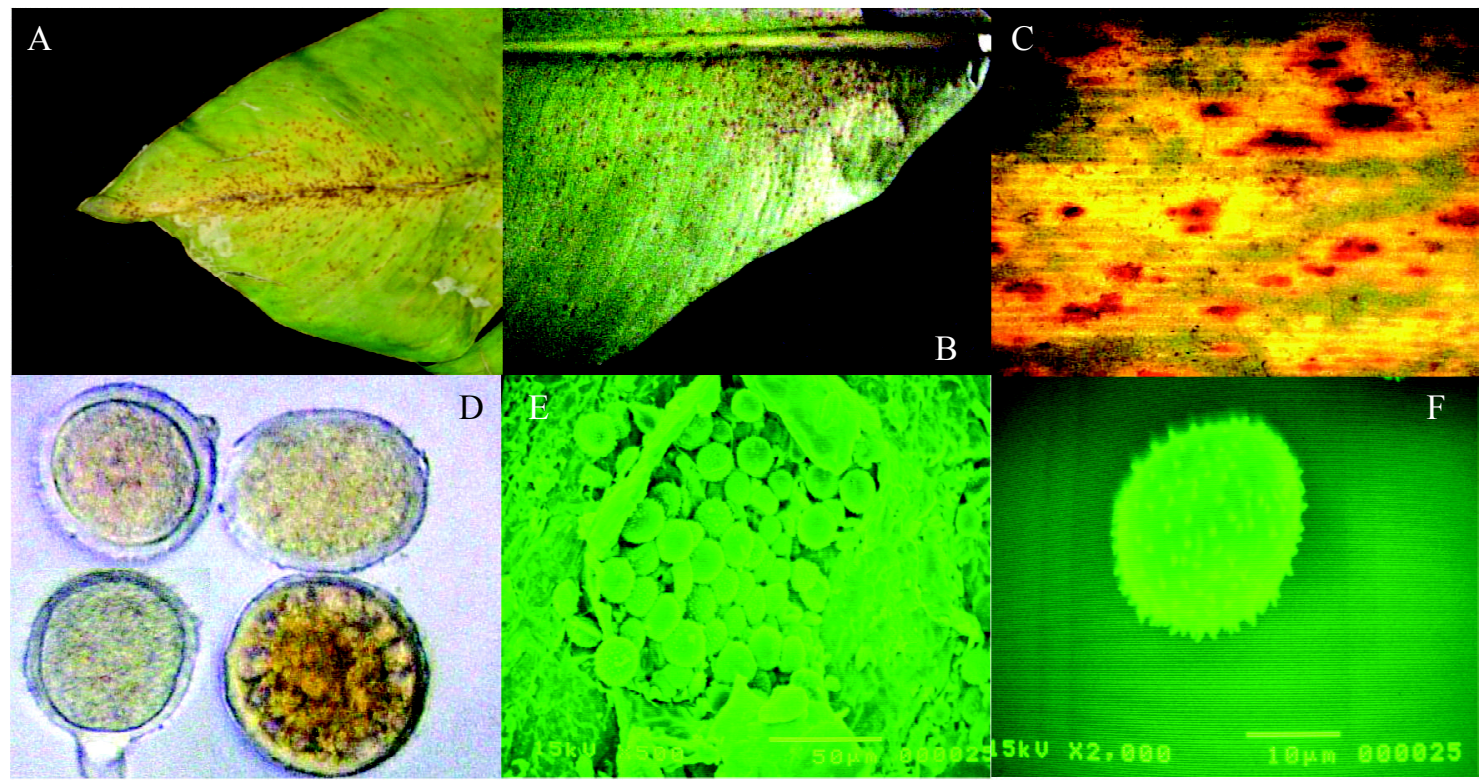

Figura 1. Sintomas de ferrugem da helicônia em folhas: A - face adaxial; B e C - faces abaxiais. Estruturas de Puccinia heliconiae visualizadas em microscópio óptico: uredósporos, D. Estruturas de P. heliconiae visualizadas em microscópio eletrônico de varredura: E - pústula e F - uredósporo. Fotos: Jaqueline Verzignassi 